\title{
Theory of Star Privacy Protection
}

\author{
Xiaoxuan Cui \\ North China Electric Power University, Beijing, 102206, China
}

Key Words: Stars, The right to privacy, Protection

\begin{abstract}
The privacy of stars, freedom speech of the press and the public's right to know has been conflicting. The contradiction caused by the influence of the star identity and the push of the society. Star privacy protection is not only beneficial to realize the star of their own rights and interests, is more advantageous to form a good social effect, strengthening the legal construction of our country. The definition of the scope for protection of star privacy and measures taken should combined with the reality that being violated in real life to give a reasonable conclusion.

With the advent of network, the use of microblogging, WeChat, stars and ordinary seems to be more and more close to us, we can interact with the stars easily by opening the microblogging, and we pay close attention to the life of the stars at any time, but at the same time, the private lives of celebrities is faced with great challenges, following the "sex photo" incident in 2008, Zhang Wen derailed, Zhendong Ke drugs, Haibo Huang whoring, Dan Lin derailed appear to the public immediately. Why these message appear, what is the effect, how to control the phenomenon, these are all worthy of our study.
\end{abstract}

\section{The right to privacy and the stars}

The meaning of privacy and the stars. The right of privacy concept was born in America in 1890. Harvard law school professor Louis D. Brandeis and Samuel warren, D in the fourth stage of the Harvard Law Review published a paper titled "privacy", which is regard as a "pioneering", the theory of privacy was born with the paper published. Understanding of the right of privacy, different scholars have different opinions in our country. I recognized that"the right of privacy is a natural person's personal right, about keeping and controlling the information which is about their personal, personal information that is none of the public interest and private activity". Privacy should not contain content related to the public interest. Because privacy is nothing to do with the public interests, group interests, and usually it means a space that the parties prohibited others to enter.From this concept, we can see that the constitution of privacy include three aspects: first of all, the objective aspect of privacy must have nothing to do with the public interest, secondly, the subjective aspect must be that I don't want to others know or others have inconvenience interference situation, object aspect refers to the individual private and the private sector.

Chinese dictionary in the interpretation of the star as "ancient book refers to Venus. Old time, it refers to the famous woman in communication field; now it refers to who have certain influence in a field. Referring to the famous actors, singers, entertainers and athletes, etc." That is easy to understand, so I won't do too much analysis and explanation.

The meaning of protecting the privacy of stars. It is the "star" identity, which makes their privacy special compared with the average person. In order to gain the public's popularity and favor, satisfy the curiosity of the public and the right to know, they volunteer to revealing something that seems more intimate things to ordinary people, such as: marriage status, age, height, birthday, hobbies, work plan, travel plans, and so on. This makes their personal information and life more widely exposed in the public eye. Over time, the exploratory of public will be stronger , the media in order to improve the reputation, comply with the requirements of the public, and even beyond the exploration areas of the public, overly reported star's private information and life , which make up privacy infringement to the star.

At this point, the key are how to choose and what is the meaning of protecting the privacy of the 
star. I think the star's privacy should be protected specially, because the star's privacy has special significance.

Personal aspects: Protecting stars' privacy is benefit for the star directly, their lives will be greatly avoid the interference of others when the thing they do not want exposure can be very good secrecy, such us their housing information, personal contact, marriage status. And it also can greatly reduce the contradiction between stars and fans, entertainment and so on, reduce the things like Xiaogang Feng cursed the media in public because the media divulge his home address ,YapengLi fisted paparazzi to protect his daughter, Yan Li, even threatened to "see once to play once" .Stars' life will become more calm, and comfortable.

Social aspects: Stars' every action has a huge influence on society. Fan efficiency refers to the fans worship idols and imitation their behavior, etc. Stars must have a large number of fans, the fans don't have the same age and cognitive level. Under ages' idol worship is a huge security risk. Celebrity scandals or fault action once be exposed, teenagers who have not yet form a correct cognitive are likely to imitate something that they think is "cool" behavior, such as drug abuse, fighting and so on. Stars express dissatisfaction with the expose of private life in front of the media, fans also can attack the media to protect the star, or curse on Weibo, or interfere the normal order of market by using other bad means, etc. Due to the large number of fans, any actions of them may have a significant impact to the society. Protecting the privacy of stars, therefore, can reduce unnecessary disputes, bring to good social effects.

The legal system aspects:The United States has enacted a large number of legal protection of privacy, such as Rights of the family education and privacy (1974), Bill of privacy protection (1980), etc. Many countries like Germany, France, Sweden, Japan, also attaches great importance to the protection of citizens' right to privacy[1]. In our country, "the right of privacy" is the first time to be written in the Tort liability law, other rights related refer to the Constitution of our country, the General principles of the civil law, Criminal law and other laws. Such as personality right, reputation, image rights, the right of honor, communications, residences, etc. They don't support a specific system, and deviation the present situation of the privacy protection. If we can form a system of star's privacy legal protection, improve the relevant legislation in our country, we must can follow the international trend, make the legal system of our country plentiful.

\section{Second, the scope of stars' privacy protection}

Illegal behavior is not protected. Stars' privacy must be established in the legal scope. Law is the lowest requirement of society people and the scope of stars' privacy must be consisted with legal requirements at first. Because gambling, prostitution, drug abuse, smuggling and other behaviors are regarded as crime or violation of the law in Chinese criminal law, so these behaviors shall not be regarded as privacy, and these cases shall be heard in public unless the related laws prohibit.

Voluntary exposure to privacy shall not be regarded as privacy. We already mentioned before that because of the "star" identity, stars are doomed to expose some private information to improve their popularity. For this part of the voluntary exposure to privacy of the stars, I think we should respect their own choices, should not be served as "the privacy" in this article, but it must be the thing that the laws don not exhibit to be exposed, and the stars also should take responsibility themselves of the exposure, and take the consequences of the exposure.

The appropriate protection to violation of moral behavior. I think the violation of morality refers to the judging standards do not conform to the normal, but not illegal behavior. For example: Guanxi Chen's "sex photos" case in 2008, Rong Ma derailed broker and Baoqiang Wang divorce case, Zhang Wen and Dan Lin derailed case, etc. After these cases are exposed, the parties of the events are under great pressure by public, and caused bad influences to themselves, their families and career. I think these personal problems, especially the problems involving marriage or family, should be dealt only by the husband and wife or other family members, we as a bystander, should keep rational and not to participate in. Standing in their shoes, stars are also normal person, problems in their private lives should not be so amplifier, and public opinion should not make them 
too much pressure. But not including bigamy.

\section{Third, protection to stars’ privacy}

\section{Legal protection.}

Set up separate legal regulations to protect stars privacy. In our Chinese Constitution, there are rules about personal dignity (article 38), right of residence (39), communication freedom and secret rights (40). There are also rules about the right of name, the name of the article (99), image (100), reputation (101), and the protection of the right of honor (102) in Civil Law. Such are also mentioned in Criminal Procedure Law and Civil Procedure Law. That rights are related to privacy, so there is no need to set up a specific law for them. But for such special group, stars, setting up separate legal regulation is necessary. To set up this kind of separate legal regulations, as far as I am concerned, should combined with the actual situation and cases, not only sum up current rules. Then the separate legal regulation can be a supplement of current legal system.

Developing Press law. Compared with the freedom of speech, the media freedom of speech has particularity, the restrictions on it is different from the normal limits of free speech. It should be on the view of the professional media, and be a legal constraints. Therefore, I believe that setting up "press law" is necessary. The press law should follow the principle that "the stars all reported to respect personal privacy", then covers the access to information, methods, information authenticity, legality, and the rights of the reporting people, reported information. Details should be ruled clearly.

\section{Moral protection.}

The stars must learn to protect themselves. Stars should strengthen the protection of their privacy. When their rights are violated, they should take up the weapon of the law and protect themselves, like Fei Wang suing Tianya online network Technology Company and Lingyun Interactive Information Technology Company, a natural person Leyi Zhang suing as a nature person. Only if the stars begin to attach the importance and take protective measures, can make the infringer fear, and know their own mistakes. Then that stars can avoid the occurrence of such violations mostly.

The news media insist on ethics and moral. In terms of morality, the news and media reporters have to obey their own professional ethics during earning money. Media man should strictly follow the rules in Chinese journalists professional code of ethics, especially that media man must "main the right of citizens which is ruled by constitution, never tell tales, never slander others, get news through legal and proper way, respect the statement and requirements of interviewees."[4] They should also obey public morality and create a good public opinion atmosphere.

\section{Improve the aesthetic taste and judgment of the masses.}

Public should enhance their judgment and analysis ability. When meeting the private information of the stars, keep rational attitude and don't follow that suit. Always keep in mind that I am just an outsider, although concerned about idols, but not for the star's private affairs. The stars can take their own measures, no matter what the end results. Public should not give them too much pressure, to their normal lives. For the stars, being given some space is the best support and love to them. When the public attention is no longer involved in the privacy of stars daily chores, there will be no audience media reporting only on privacy affairs of the stars.

\section{References to journal papers:}

[1] H.X. li. The limits of reporting the entertainment stars' privacy [J]. The press. 2004:44-45 (In Chinese)

[2] L.Y. Yuan. On the protection of the privacy of public figures - Talking about the star entertainment news reports about privacy [J]. Journal of Ningde Teachers'College (Philosophy and Social Sciences Edition) , 2008(4):15-19 (In Chinese)

[3] D.B.N. Song. The Legal Protection on Star's Privacy [J]. Journal of HuBei Adult Education Institute. 2014, 20(2):72, 96-97 (In Chinese)

[4] Z. Ru. Research on range of protection to Entertainment stars' privacy [J]. The rule of law and society. 2014:237-238 (In Chinese) 
[5] X.S. Pan.On protection and restriction of privacy right of stars [J]. Journal of Shenyang University of Technology (Social Science Edition), 2016, 9 (6):567-570 (In Chinese)

[6] L.M. Wang. The Restriction and Protection of Public Figures' Personality Rights [J]. Academic Journal of Zhongzhou, 2005 (2): 92-98 (In Chinese) 